\title{
Temporal patterns in the activity density and sex ratio of isopods (Oniscidea, Isopoda) along an urbanization gradient in Denmark
}

\author{
F. Vilisics ${ }^{1}$, Z. Elek ${ }^{2}$ and G. L. Lövei ${ }^{3}$ \\ ${ }^{1}$ University of Helsinki, Faculty of Bio- and Environmental Sciences, Department of Environmental Sciences, Urban \\ Ecology Research Group, FI-00014 Helsinki, P.Box 65, Viikinkaari 2, Finland \\ ${ }^{2}$ MTA-ELTE-MTM, Ecology Research Group, Biological Institute, Pázmány Péter sétány 1C, H-1117 Budapest, \\ Hungary \\ ${ }^{3}$ Department of Agroecology, Aarhus University, Flakkebjerg Research Centre, DK-4200 Slagelse, Denmark. \\ Corresponding author.E-mail: gabor.lovei@agro.au.dk
}

Keywords: Activity patterns; Female-dominated sex ratio; Seasonal activity; Urbanization.

\begin{abstract}
Urbanization effects on terrestrial isopod (Isopoda, Oniscidea) populations were studied in forested areas along a rural-to-urban gradient including a native beech forest, suburban and urban forest fragments in Sorø, Denmark. The seasonal activity patterns of the dominating species (Oniscus asellus, Philoscia muscorum and Porcellio scaber) indicated differences among the areas, but these patterns were idiosyncratic. There were more females than males in most areas. The seasonal patterns of males and non-gravid females were similar and often bimodal; gravid females showed markedly different, usually unimodal activity patterns. Temporal changes of sex ratios were - in each species - characterized by an early summer activity peak of males, followed by the activity peak of gravid females. We suggest that these trends might indicate a reproduction-driven surface activity of males. The small response of the three isopod species to urbanization may reflect their wide ecological tolerance as well as the "soft management" of the urban park.
\end{abstract}

\section{Introduction}

Urbanization is a major factor that severely modifies natural landscapes through not just isolating, fragmenting and destroying natural habitats, but altering their abiotic conditions as well (Grimm et al. 2008). Urban areas are characterized by an increased density of humans and features related to human needs and activities. As human needs are similar world-wide, cities -apart from obvious differences due to locality - share some common features in their structure and function: the city matrix consists of densely built-up zones including residential, commercial, industrial areas and facilities of public services. Impervious surfaces, air-, noise-, and light pollution, an elevated mean temperature ("heat island effect") and managed green areas (e.g., parks, gardens) are among the most typical urban features (Andreev 2004).

The effects of urbanization can usefully be studied following an "urbanization gradient", stretching from the areas outside the city, where the original habitat is still present, through the suburbanized areas surrounding a usually densely built city core (Niemelä et al. 2000). This general similarity allows the study of general trends concerning the biological effects of urbanization in different parts of the world.

Urbanization leads to major changes in local faunas. The composition of urban epigaeic arthropod assemblages generally differs from the original assemblages of rural areas (Magura et al. 2010). Due to a combination of the abi- otic factors mentioned earlier, and despite local extinctions of less tolerant species (Zapparoli 1997), cities can harbor higher arthropod species diversity than the surrounding, less urbanized areas (isopods: Vilisics and Hornung 2009; insects: Sattler et al. 2010). While alien organisms are most likely attached to artificial habitats (greenhouses, gardens, industrial zones) (e.g., Roques et al. 2009), forested urban habitats (e.g., parks) are generally inhabited by native species of wide tolerance (Elek and Lövei 2005, 2007, Hornung et al. 2007, Bogyó and Korsós 2009, Horváth et al. 2014). Urbanization can also cause altered dominance patterns of trophic groups (decreased abundance of predators: Pavao-Zuckerman and Coleman 2007), and biotic homogenization (Holway and Suarez 2006, Devictor et al. 2007).

Terrestrial isopods are common members of the invertebrate fauna of the European rural and urban environments, except for the boreal zone (Schmalfuss 2003), and contribute to decomposition of dead plant matter (Coleman and Hendrix 2000). Therefore urbanization can affect nutrient cycling, via impacts on isopods. However, isopod diversity is much lower in temperate Europe, than those of ground beetles or spiders. For example, Denmark has 29 isopod (Meinertz 1964), vs. 302 carabid (Anichtchenko et al. 2012) and 545 spider species (Scharff and Gudik-Sørensen 2006). Consequently, changes in species presence or diversity cannot be very large because of a tight "parameter space". This leads to the consideration of other response variables that can be sensitive 
to the effects of urbanization. The seasonal activity patterns and temporal changes of demographic composition of isopod populations (Farkas 1998, Zimmer and Topp 1999, Araujo and Bond-Buckup 2005), hold promise to serve as suitable response variable. Seasonal variation in the sex-ratio of marine (Arrontes 1992) and terrestrial (Farkas 1998, Dias and Sprung 2003) isopods have been reported, but the changes in the sex ratio caused by environmental factors remain unexplored.

The Fisherian principle states that the sex ratio of sexual species is approximately 1:1 (Fisher 1930). Most isopod populations, however, have a sex ratio dominated by either females or males (Achouri et al. 2008), and the ratios are prone to show temporal and spatial changes (Dias and Sprung 2003). These deviations from the Fisherian sex ratios can carry adaptive benefits (Godfray and Werren 1996). Seasonal dynamics, however, is often treated ad hoc in arthropods, and these make it difficult to compare various locations, seasons, or species. Fazekas et al. (1997) suggested formalizing the description of seasonal dynamics by using a quartile method, which sets precise rules to identify the main activity periods, and the seasonal activity peak, at least for univoltine species. This method seems suitable for comparing seasonal dynamics in a more standardized way.

Our goal was to formally describe, using the quartile method, the seasonal dynamics of the most common species of isopods along the urbanization gradient in Sorø, Denmark, and compare them between urbanization stages and years. Further, we tested the hypothesis that the increasingly stressful conditions along the urbanization gradient will lead to a distinct female domination, while isopod sex ratio remains closer to a Fisherian 1:1 ratio in the original, forested area.

\section{Material and methods}

\section{Sampling area and methods}

The study areas are situated in the vicinity of Sorø town (55 $26^{\circ} \mathrm{N}$; $11^{\circ} 34^{\prime} \mathrm{E}$, population 7764 in 2012), in West Zealand, Denmark, where three studied areas (rural, suburban, urban) represented different urbanization stages.

The studied habitat was a beech (Fagus sylvatica L.) forest; a once-continuous forest area around Sorø, which has been fragmented into several different-sized forest patches. The history of the forest is well documented, and the suburban and park areas contain elements of the original forest. The "rural" area was in the continuous beech forest area of $6000 \mathrm{ha}$, the edge of which was ca. $3 \mathrm{~km}$ from the town center. It has a dense canopy, sparse shrubs layer and a seasonally dense herb layer.

The suburban forest fragments were situated in the outskirts of the town. Apart from beech, common ash (Fraxinus excelsior L.), was also present in the canopy; a dense shrub and herb layer with nettle (Urtica dioica L.) characterized this area. A moderate level of urbanization is represented by a garden allotment zone, a cemetery, paths and gravel roads, and a ditch separating the suburban area from a low-lying, wet forest patch. The „urban” area was selected in the Sorø
Akademi park complex, where remnants of native trees and non-native ones form forest patches. This park is under "soft management": there are only gravel paths, rotting logs are usually left in place, cut grass, litter and branches are returned to the understory of forest patches, and there are no fertilizers or herbicides used in the park. The park complex is partly bordered by a lake on one side, and by the built-up urban core on the other.

We used pitfall traps set according to the Globenet protocol (Niemelä et al. 2000, Elek and Lövei 2005). We selected four sites within each urbanization stage (rural, suburban, urban) and placed 10 traps in each site, a total of 120 traps. Traps were emptied fortnightly between early May and midOctober in 2004. In 2005 we applied an intermittent sampling method by having traps open during every second fortnight to reduce the sampling intensity (Sapia et al. 2006). The catch was sorted in the laboratory under a stereo microscope (max. $40 \times$ magnification), and carabids, spiders and isopods were separated, and kept in individual vials in $70 \%$ ethyl alcohol until identification.

\section{Data analyses}

Seasonal activity was formally described by the "quartile method", following Fazekas et al. (1997). Captures (total number of individuals per fortnight) were first converted to cumulative values. The date of peak activity is the date when the total number of individuals caught reached $50 \%$ of the total number collected. The beginning and the end of the main activity period were defined as the dates between the first and the third quartiles, when $25 \%$ and $75 \%$, respectively, of the total number of individuals were captured. The "early activity period" extended from the start of the activity to the beginning of the main activity period, and the "late activity period" was defined as the period from the end of the main activity period until activity has ceased.

We analyzed the activity density of three dominant species Oniscus asellus L., 1758, Philoscia muscorum (Scopoli, 1763), Porcellio scaber Latreille, 1804, that comprised $96.5 \%$ of the total catch $(129,366$ individuals out of six species). Comparison of species activity densities among rural, suburban and urban areas was carried out by Kruskal-Wallis rank sum test.

Since pitfall trapping is suitable to detect surface active isopods, soil and bark-dwelling species [Haplophthalmus mengii (Zaddach, 1844), Trichoniscus pusillus (Brandt, 1833)] were excluded from analyses.

As gravid (ovigerous) females bear eggs and are not yet ready for new copulations, we omitted their data when calculating sex ratio. The situation is the same for post-hatching females that carry an empty marsupium, and they were also excluded. This way we considered the "operational sex ratio" (Araujo and Bond-Buckup 2005), but we refer to it as "sex ratio" unless noted otherwise. We observed the sex ratios of populations of the three common species in each area Deviations from a hypothetical 1:1 ratio were tested with a $\chi^{2}$ test. 


\section{Results}

Species composition and abundance

The samples were collected on 17 sampling dates in 2004 and 2005. The total catch (in 2004 and 2005 together) of isopods consisted of eight species: Armadillidium vulgare (Latreille, 1804), Ligidium hypnorum (Cuvier, 1792), H. mengii, O. asellus, P. muscorum, P. scaber, Trachelipus rathkii (Brandt, 1833) and T. pusillus. In 2004, a total of 98927 individuals of the six species were collected. Three species made up $96 \%$ of this total: P. scaber (47\% of total catch), O. asellus (28\%) and P. muscorum (21\%) (Table 1).

In 2004, there was no difference in species composition among the various urbanisation stages, but significant differences among the areas were found in the numbers of individuals $\left(\mathrm{H}_{(2, \mathrm{~N}=120)}=61.01 ; \mathrm{p}=0.004\right)$. The overall activity density was lowest in the rural area $(10,345$ individuals in total), lower than in either the suburban $(34,112)$ or the urban (54470) stages.

In 2005, we found the same tendencies, but T. rathkii was missing from the rural area. The three most frequent species were $P$. scaber (16,335 individuals, $53.6 \%$ of total catch), $O$. asellus (8091, 26.5\%) and P. muscorum (5195, 17\%) (Table 1), contributing $97.1 \%$ of the total catch. Similarly to the previous sampling period, the overall activity density was the lowest in the rural (1970), followed by the suburban (8751) and the urban $(19,718)$ urbanization stages.

\section{Seasonal activity}

The seasonal changes of activity densities showed great differences among species and areas in 2004 (Fig. 1). In 2005 , seasonal activity patterns showed greater differences among urbanization stages than in the previous year (Fig. 2). O. asellus and P. muscorum were present in all areas at every sampling occasions, in both years. The occurrence of $P$. scaber was sporadic in the rural area; this species was missing from the collections on several occasions in both years.

The main activity periods of the most common species were between early June and late August-early September, whereas activity peaks generally fell between mid-July and mid-August, in both years (Fig. 2).

The length of the main activity period of P. muscorum was consistently shorter in the forest than in the more advanced urbanization stages, in both years. This species had the longest main activity period in the suburban and urban areas in 2004 (nearly three months in the summer, 4 June - 30 August).

Activity peaks of gravid females of the three common species did not overlap within a given area (rural, suburban or urban) in 2004 (Fig. 3). The earliest peak occurred for P. scaber (in the urbanized areas only), followed by P. muscorum, and $O$. asellus peaked in late summer. In 2005, however, overlapping activity peaks occurred in several locations (Fig. 3).
Sex ratios

The sex ratio was female-dominated for all three species in each area in both years (Table 2). The greatest differences occurred in the sex ratios in the rural area, except for $O$. asellus.

There was a remarkable seasonal variability in surface activity of the sexes (Figs 4 and 5 ). Deviations from the 1:1 ratio were often significant (Table 2) for P. muscorum and P. scaber, while $O$. asellus rarely showed significant differences in the rural area in 2004 and the urban areas in either year (Table 2).

The ratio between reproductive vs. non-reproductive females was highest in the forest and lowest in the urban park (Table 3). The males to gravid females ratios showed remarkable differences among the urbanisation stages (Table 4) but they were consistently higher in the urbanized areas
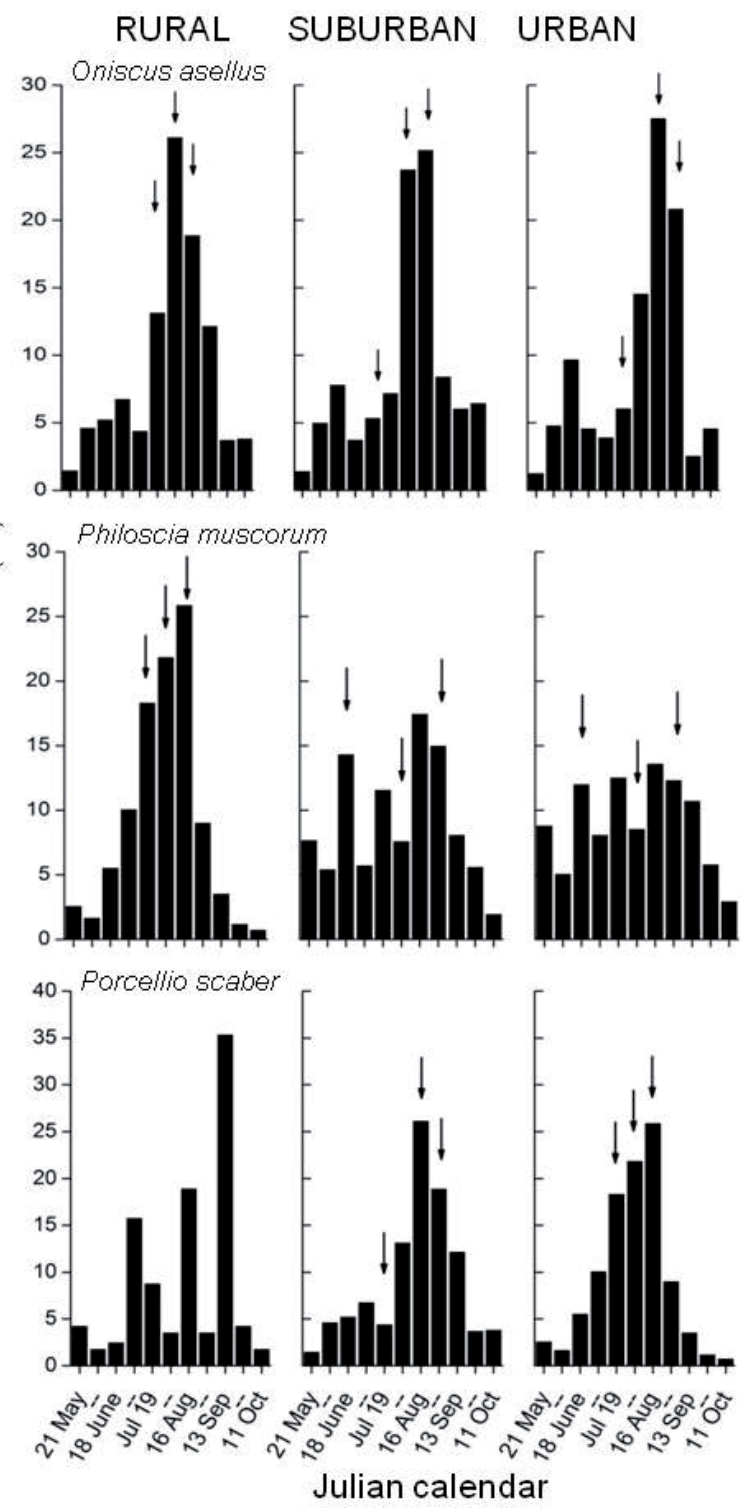

Figure 1. The relative activity densities of isopods in Sorø, Denmark in 2004. Arrows indicate the beginning and end of the main activity period, and the activity peak. 
Table 1. Total numbers of isopods captured in three areas representing different urbanization stages in Sorø, Denmark in 2004 and 2005.

\begin{tabular}{lrrrrrrr}
\hline Species & \multicolumn{3}{c}{2004} & & \multicolumn{3}{c}{2005} \\
\cline { 2 - 4 } \cline { 7 - 8 } & Forest & Suburban & Urban & & Forest & Suburban & Urban \\
\hline Porcellio scaber & 286 & 12570 & 33609 & & 45 & 3031 & 13259 \\
Oniscus asellus & 2769 & 11989 & 13131 & & 1079 & 3255 & 3757 \\
Philoscia muscorum & 7230 & 6936 & 6800 & 831 & 1917 & 2447 \\
Armadillidium vulgare & 45 & 1503 & 252 & 5 & 249 & 127 \\
Ligidium hypnorum & 11 & 1013 & 443 & & 10 & 296 & 62 \\
Trachelipus rathkii & 4 & 101 & 235 & & 0 & 3 & 66 \\
Number of species number & 6 & 6 & 6 & 5 & 6 & 6 \\
Overall total & 10345 & 34112 & 55112 & 1970 & 8751 & 19718 \\
\hline
\end{tabular}

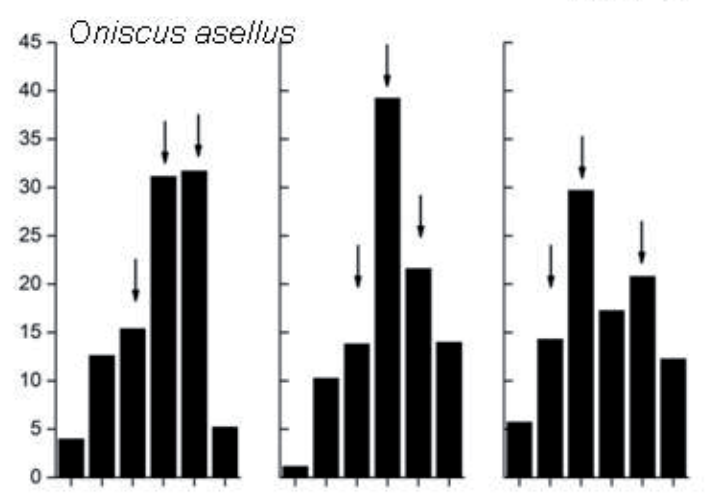

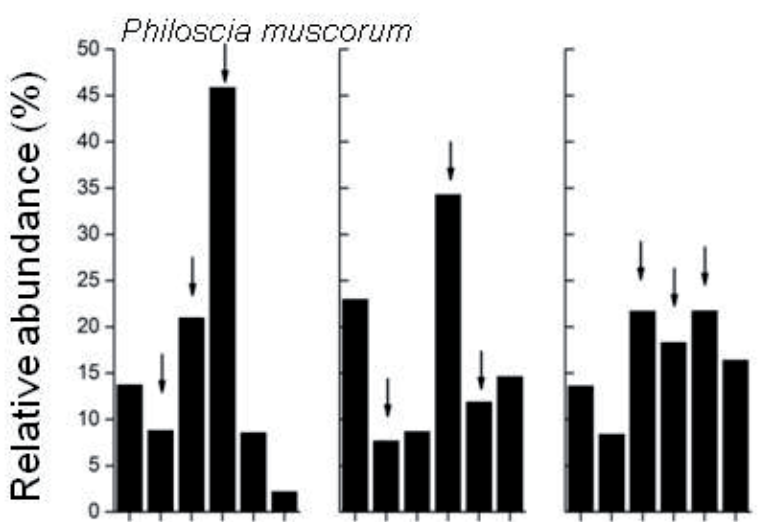

Porcellio scaber
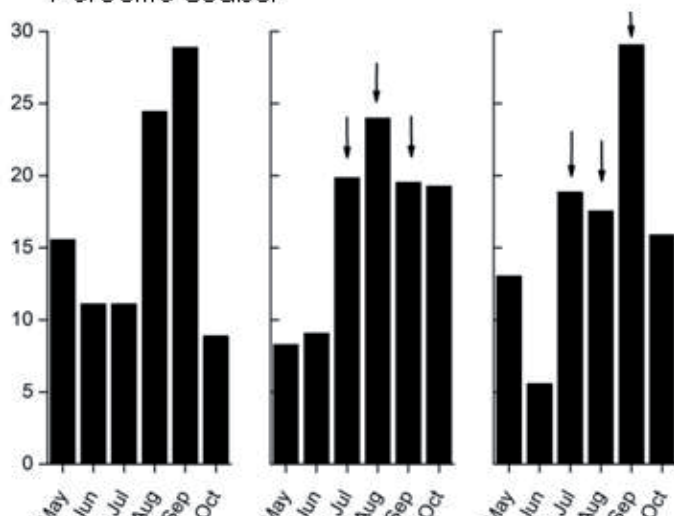

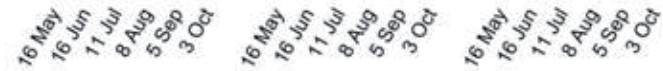

\section{Julian calendar}

Figure 2. The relative activity densities of isopods in Sorø, Denmark in 2005. Arrows indicate the beginning and end of the main activity period, and the activity peak.

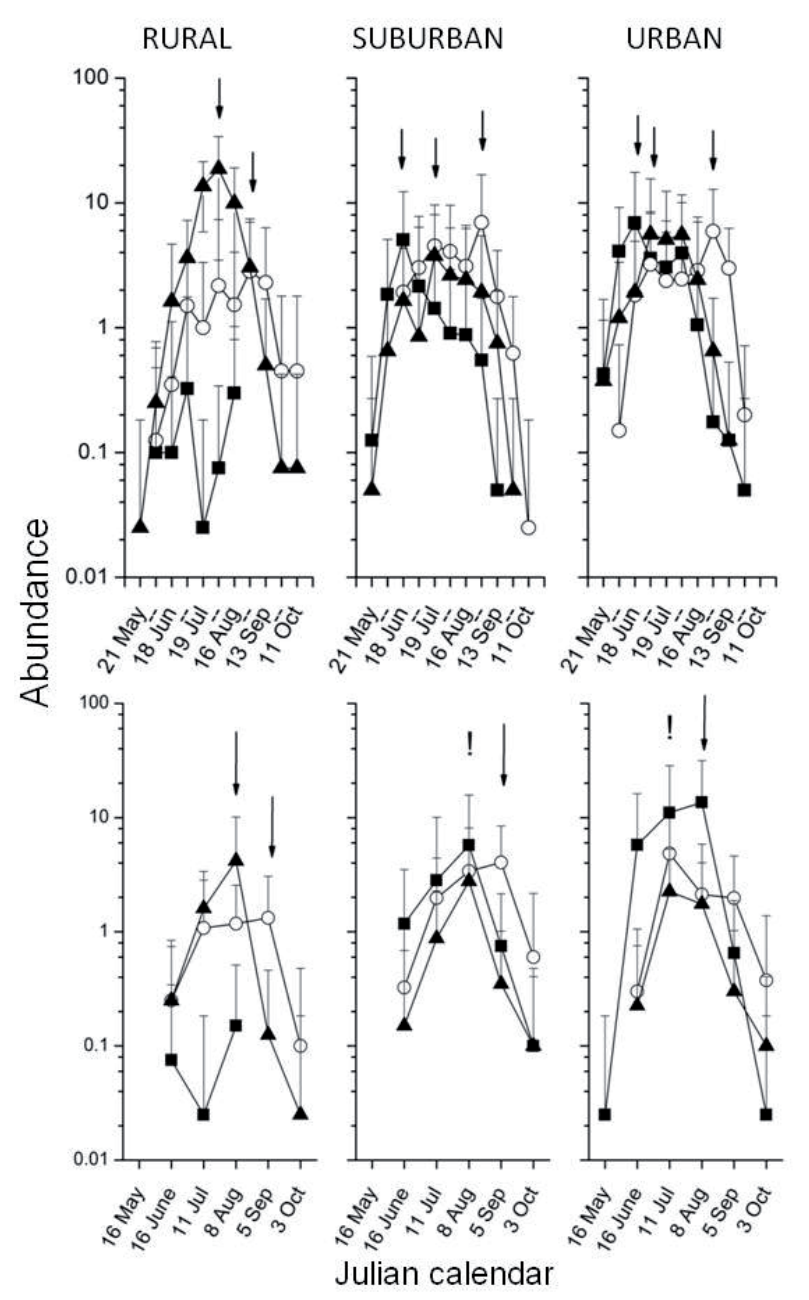

Figure 3. Seasonal patterns of epigaeic activity of reproductive females of $O$. asellus, P. muscorum, P. scaber in Sorø in 2004 and 2005. Legend: $\mathbf{m}$ : P. scaber; о: O. asellus; $\mathbf{\Delta}$ : P. muscorum. Arrows indicate activity peaks. ! shows overlapping peaks. 
Table 2. Results of a $\chi^{2}$ test of female-dominated sex ratios in four abundant species along the urbanization gradient in Sorø, Denmark in 2004 and 2005. The letter $\mathrm{F}$ indicates significant deviation from equality towards females.

\begin{tabular}{|c|c|c|c|c|c|c|}
\hline \multirow[t]{2}{*}{ Year, Species } & \multicolumn{2}{|c|}{ Forest } & \multicolumn{2}{|c|}{ Suburban } & \multicolumn{2}{|c|}{ Urban } \\
\hline & $\chi^{2}$ & $\mathrm{P}$ & $\chi^{2}$ & $\mathrm{P}$ & $\chi^{2}$ & $\mathrm{P}$ \\
\hline \multicolumn{7}{|l|}{2004} \\
\hline Porcellio scaber & 40.78 & F 0.000 & 340.8 & F 0.000 & 901.6 & F 0.000 \\
\hline Oniscus asellus & 9.36 & F 0.0022 & 108.9 & F 0.000 & 97.4 & F 0.000 \\
\hline Philoscia muscorum & 696.4 & F 0.000 & 171.2 & F 0.000 & 261.8 & F 0.000 \\
\hline \multicolumn{7}{|l|}{2005} \\
\hline Porcellio scaber & 6.42 & F 0.04 & 42.9 & F 0.000 & 7.84 & F 0.034 \\
\hline Oniscus asellus & 2.17 & 0.1 & 0.02 & 0.8 & 29.1 & F 0.000 \\
\hline Philoscia muscorum & 28.1 & F 0.000 & 14.2 & F 0.000 & 77.8 & F 0.000 \\
\hline
\end{tabular}

RURAL SUBURBAN URBAN

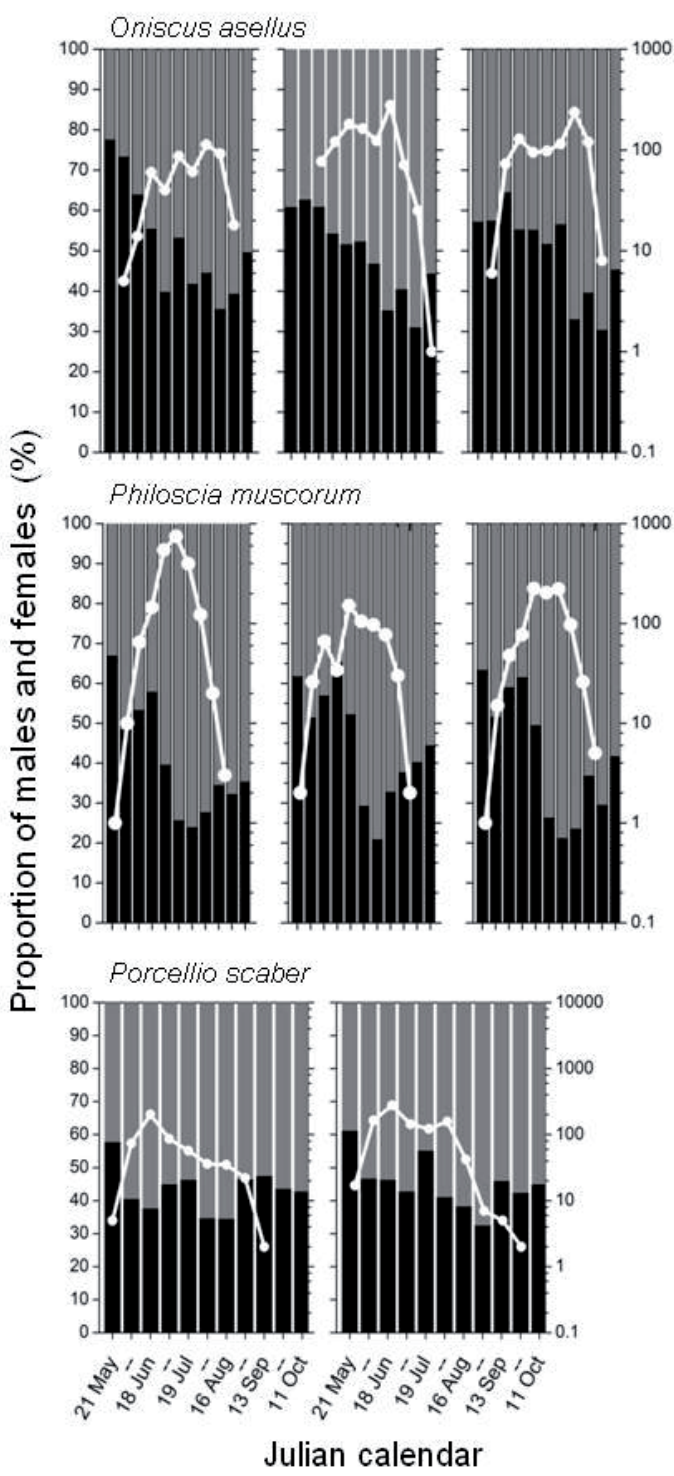

Figure 4. Relative abundance (\%) patterns of sexes (columns) and surface activity of reproductive females (white line) of $O$. asellus, P. muscorum, and P. scaber in Sorø in 2004. Data on $P$. scaber from the rural area has been omitted. Grey columns show females; black columns represent the contribution of males.

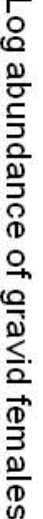

\section{RURAL SUBURBAN URBAN}

Oniscus asellus
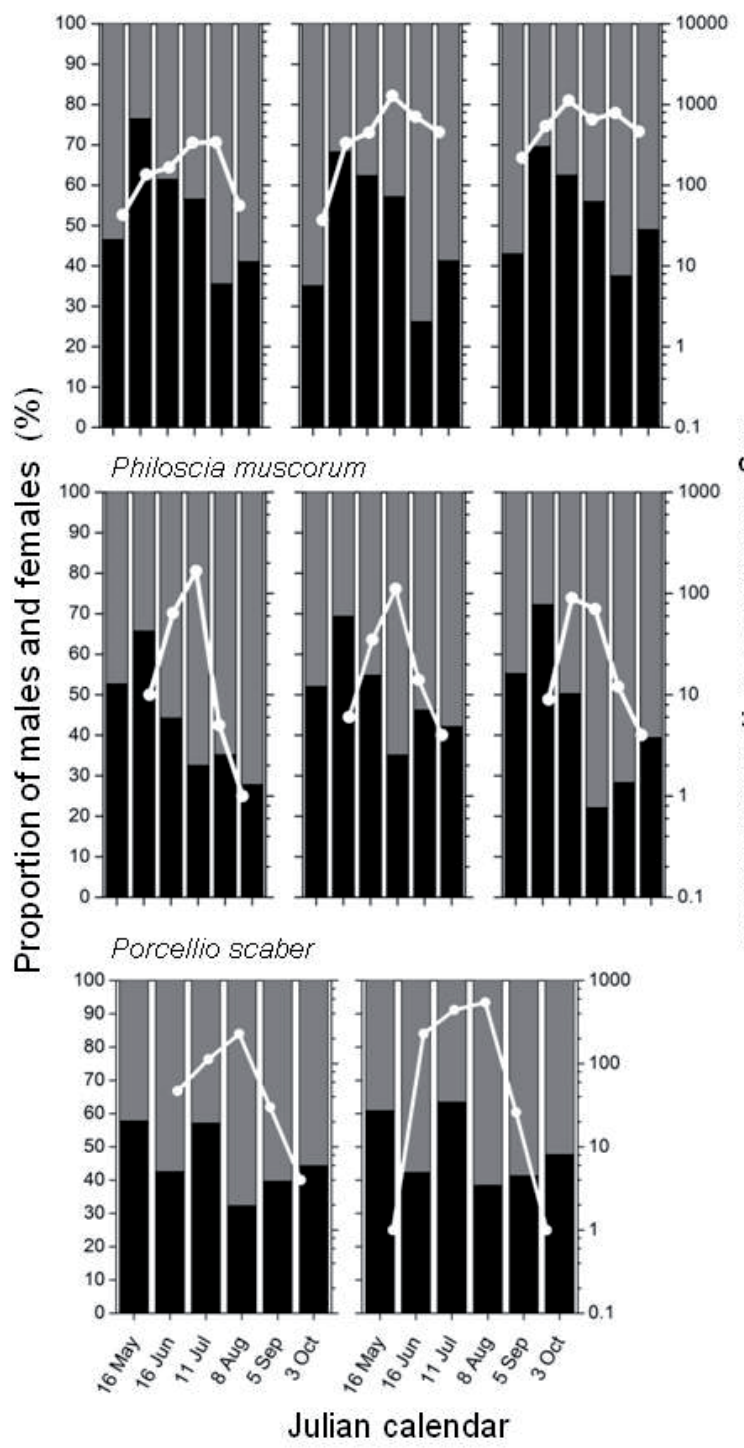

Figure 5. Relative abundance (\%) patterns of sexes (columns) and surface activity of reproductive females (white lines) of $O$. asellus, $P$. muscorum, and $P$. scaber in Sorø in 2005. Data on $P$. scaber from the rural area has been omitted. Grey columns show females; black columns represent contribution of males. 
Table 3. Percentage and activity peak of gravid females from the total number females captured along the urbanization gradient in Sorø in 2004 and 2005. *: no available data

\begin{tabular}{|c|c|c|c|c|c|c|}
\hline \multirow[t]{2}{*}{ Year, Species } & \multicolumn{2}{|c|}{ Forest } & \multicolumn{2}{|c|}{ Suburban } & \multicolumn{2}{|c|}{ Urban } \\
\hline & $\begin{array}{c}\text { Gravid, } \% \\
\text { females }\end{array}$ & $\begin{array}{c}\text { Peak acvitiy } \\
\text { date }\end{array}$ & $\begin{array}{c}\text { Gravid, \% } \\
\text { females }\end{array}$ & $\begin{array}{c}\text { Peak activity } \\
\text { date }\end{array}$ & $\begin{array}{c}\text { Gravid, \% } \\
\text { females }\end{array}$ & $\begin{array}{c}\text { Peak activity } \\
\text { date }\end{array}$ \\
\hline \multicolumn{7}{|l|}{2004} \\
\hline Porcellio scaber & * & $*$ & 16 & 2 Aug & 11.7 & 2 Aug \\
\hline Oniscus asellus & 33.4 & 16 Aug & 30.9 & 30 Aug & 12.3 & 16 Aug \\
\hline Philoscia muscorum & 43.4 & 2 Aug & 14.7 & $19 \mathrm{Jul}$ & 24.3 & 2 Aug \\
\hline \multicolumn{7}{|l|}{2005} \\
\hline Porcellio scaber & * & * & 20 & 8 Aug & 15.9 & $11 \mathrm{Jul}$ \\
\hline Oniscus asellus & 23.7 & 8 Aug & 20.2 & 8 Aug & 18.4 & $11 \mathrm{Jul}$ \\
\hline Philoscia muscorum & 33.4 & 8 Aug & 14 & 8 Aug & 11.4 & $11 \mathrm{Jul}$ \\
\hline
\end{tabular}

Table 4. Male to reproductive female ratios along the urbanization gradient in Sorø in 2004 and 2005. *: no available data.

\begin{tabular}{lccc}
\hline Year, Species & Forest & Suburban & Urban \\
\cline { 1 - 1 } 2004 & & & \\
\cline { 1 - 2 } Porcellio scaber & $*$ & 4.48 & 6.12 \\
Oniscus asellus & 2.66 & 2.18 & 6.8 \\
Philoscia muscorum & 1.21 & 4.95 & 3.39 \\
\hline 2005 & & & \\
\cline { 1 - 4 } Porcellio scaber & $*$ & 3.15 & 5.02 \\
Oniscus asellus & 3.52 & 3.92 & 5.3 \\
Philoscia muscorum & 1.37 & 5.3 & 5.4 \\
\hline
\end{tabular}

(suburban and urban) than in the rural forest. O. asellus showed a rather similar pattern in both years, with relatively low male:gravid female ratios in the forest and suburban habitats, while high ratios in the urban areas.

\section{Discussion}

\section{Species composition and richness}

Urban ecosystems usually show contrasting floras and faunas in comparison to the surrounding native species pools (Niemelä et al. 2011). A higher habitat heterogeneity in urban areas may lead to an increased species richness of arthropods (McIntyre 2001, Magura et al. 2010, Sattler et al. 2010), because specific urban habitats may prove suitable for a variety of species including cosmopolitans, native habitat specialists, intra-European and exotic aliens (e.g., Vilisics and Hornung 2009, Cochard et al. 2010).

Concerning isopods and millipedes (Diplopoda, Myriapoda), cities mostly contain species of wide European distribution (e.g., Hungary: Bogyó and Korsós 2009, Switzerland: Vilisics et al. 2012). As expected, species richness or diversity trends along the urbanisation gradient show only minor differences in Denmark (Vilisics et al. 2007).

\section{Seasonal activity patterns}

The initial sampling protocol of Globenet has been set to cover the main activity period of carabid beetles (Niemelä et al. 2000), therefore our results do not represent the whole sea- sonal patterns of isopods. Although many species of woodlice show surface activity throughout the year (e.g., Tuf 2003), their main activity period is between spring and autumn, so our data can be considered generally representative and useful for comparative purposes.

The seasonal activity patterns of the dominating species indicated differences among the areas, but the patterns were idiosyncratic. Species co-occurring in our study area, $O$. asellus, P. muscorum and P. scaber also co-exist in a broadleaf forest in the vicinity of Cologne, Germany (Zimmer 2003) where the climate regime (temperate - oceanic) is similar to our sampling areas in Denmark. Likewise, the habitat characteristics (inundation / drought) of the forests near Cologne resulted in species-specific surface activity patterns, but did not affect assemblage composition.

\section{Sex ratios and sex-dependent activity patterns}

The seasonal dynamics of isopod populations is greatly flexible and such variation is thought to provide adaptive values in a changing environment (Hornung and Warburg 1998).

In Sorø, sex ratios of the most abundant epigaeic isopods differed significantly from an expected 1:1 ratio. These results contradicted our assumptions and did not support our hypothesis of shifting sex ratios from a close-to-equal ratio in the original habitat, and gradually becoming skewed towards females in more urbanized areas. In a study of Italian orchards, T. rathkii populations responded to intensified agricultural management with increasing female dominance (Paoletti and Cantarino 2002). 
Previous reports on sex ratios show both male-dominated (e.g., Gonçalves et al. 2005) and female-dominated isopod populations (e.g., Nair 1998). Sex determination of non-Mendelian elements often overrides the sex factors of heterochromosomes in woodlice. Genetic, environmental and cytoplasmic sex determination is present in terrestrial isopods, and as a result, males can readily change to females, and vice versa (Rigaud et al. 1997).

Wolbachia is an endosymbiotic bacterium affecting a wide range of arthropods (O'Neill et al. 1997) including isopods (Bouchon et al. 1998), among others altering their reproduction by cytoplasmic (reproductive) incompatibility, and feminization of genetic males. The isopods $O$. asellus, P. scaber and P. muscorum are known hosts of Wolbachia (Cordaux et al. 2001), therefore we cannot exclude the possibility that genetically male woodlice were feminized in Sorø.

Despite the overall female-dominated sex ratios, the males generally outnumbered the reproductive females in Sorø. Such male-to-gravid female ratios were lower in the forest and highest in the urban park. In other words, only a proportionately small fraction of females were involved in mating. High food quality enhances isopod breeding (Helden and Hassall 1998), and litter palatability is affected by a combination of factors including initial nutrient content, $\mathrm{C}: \mathrm{N}$ ratio, microclimate, microbial and fungal activity. Beech litter is not very palatable to isopods (Tian et al. 1995), and this was present more in the forest than in the forested patches of the park. This may have caused the observed pattern.

At the population level, cohort splitting (Sunderland et al. 1976), a possible adaptation to changing environments (e.g., Goncalves et al. 2005) may bias reproduction activity, thus it may provide a further explanation to the low proportion of gravid females. Individuals born in the same reproductive period can form a fast- and a slow-growing group. Fast growing individuals will reproduce within the same growing season they were born, while slow growing ones mate only in the next season. Cohort splitting therefore affects the rate of reproductive females within a given cohort.

In Sorø, we found an intense spring and summer male activity in the rural forest, similar to Tylos ponticus Grebnitsky, 1874 in Portugal (Dias and Sprung 2003). This trend probably indicates a reproduction-driven male surface activity as it appears in each species analyzed, regardless of the observed habitats. Our results on seasonal activities of gravid females correspond to those of Wijnhoven (2000), who found that $P$. muscorum peak reproduction occurs in July, ending in late August. He also noted that the peak of $O$. asellus reproduction was in August, which only partly corresponds to our findings: gravid females of $O$. asellus in Sorø showed an evenly high reproduction activity from early to late summer.

Surface activity peaks of gravid females of the three dominant species showed temporal separation in 2004. Similar patterns are interpreted by Zimmer (2003) as evidence for temporal niche segregation of sympatric isopod species. Although the literature lacks a comprehensive description, we assume that the three species co-occur in Denmark (Meinertz 1964), so a temporal niche segregation among these domi- nating species is plausible. The overlapping activity peaks in 2005 may be an artefact emerging from the pulsating sampling.

Our findings prove that two common species, O. asellus and P. muscorum did not react strongly to urbanization in Sorø. Moreover, the forest patches in the park in Sorø contained a regular supply of decaying plant material, because the mown grass and cut branches and other cuttings were returned to the understory of the forested patches (Elek and Lövei 2005). This may have provided ample food resources for decomposers, including isopods. In conclusion, it is likely that the isopod species present in the park were favored by the ample food available to them because of the management regime, and encountered suboptimal quality food (beech litter) in the original, rural forest habitat. Consequently, urbanization did not have a profoundly negative influence on their activity. Their reproductive conditions were suboptimal, yet they could reach high activity densities in urban forest patches, and their effect on nutrient cycling can remain important.

Acknowledgements. We thank the support of the Sorø Akademi Stilftelse, the former Danish Institute for Agricultural Sciences, Flakkebjerg Research Center, the International School of Biodiversity Studies (ISOBIS) Aarhus, Denmark and the Hungarian Scholarship Board (ZE), Dr. H. Schmalfuss (Natural History Museum, Stuttgart) for taxonomic help, and Dr. E. Hornung (Szent István University, Budapest) for comments. This is publication no. 14 of the Danglobe Project. Author contributions: GL and ZE designed the study, and performed field sampling; ZE and FV sorted and identified the material, FV, ZE and GL made the analysis and wrote the paper.

\section{References}

Achouri, M.S., F. Charfi-Cheikhrouha and M. Zimmer. 2008. Reproductive patterns in syntopic terrestrial isopod species (Crustacea, Isopoda, Oniscidea) from Morocco, Pedobiologia 52:127-137

Andreev, V. 2004. Urban Climate and Air Quality - a Review. in: L. Penev et al. (eds.), Ecology of the City of Sofia. Species and Communities in an Urban Environment. Pensoft Publishers, Sofia - Moscow, pp. 55-82.

Anichtchenko A. et al. 2012. Carabidae of the World. http://www. carabidae.pro; accessed: 13 July 2017

Araujo, P.B. and G. Bond-Buckup. 2005. Population structure and reproductive biology of Atlantoscia floridana (van Name, 1940) (Crustacea, Isopoda, Oniscidea) in southern Brazil. Acta Oecol. 28:289-298

Arrontes, J. 1992. Sex-ratio variation in an intertidal isopod. Oikos 63:131-138.

Bogyó, D. and Z. Korsós. 2009. Effect of urbanization on diplopods Faunistical results. Természetvédelmi Közlemények 15:412-421. (in Hungarian)

Bouchon, D., T. Rigaud and P. Juchault. 1998. Evidence for widespread Wolbachia infection in isopod crustaceans: molecular identification and host feminization. Proc. Biol. Sci. 265:10811090 . 
Cochard, P.O., F. Vilisics and E. Séchet. 2010. Alien terrestrial crustaceans (Isopods and Amphipods). In: A. Roques, J.Y. Rasplus, W. Rabistch, C. Lopez-Vaamonde, M. Kenis, W. Nentwig and D. Roy (eds.), Terrestrial Arthropod Invasions in Europe. BioRisk 4:81-96.

Coleman, D.C. and P.F. Hendrix. 2000. Invertebrates as Webmasters in Ecosystems. CABI Publishing, Wallingford, UK.

Cordaux, R., A. Michel-Salzat and D. Bouchon, 2001. Wolbachia infection in crustaceans: novel hosts and potential routes for horizontal transmission. J. Evol. Biol. 14:237-243.

Devictor, V., R. Julliard, D. Couvet, A. Lee and F. Jiguet. 2007. Functional homogenization effect of urbanization on bird communities. Conserv. Biol. 21:741-751.

Dias, N. and M. Sprung. 2003. Population dynamics and production of the isopod Tylos ponticus in a Ria Formosa saltmarsh (South Portugal). In: A. Sfenthourakis, P.B. Araujo, E. Hornung, H. Schmalfuss, S. Taiti and K. Szlávecz (eds.), The Biology of Terrestrial Isopods V. (Crustaceana Monographs, 2), Brill Academic Publisher, Leiden, pp. 133-149.

Elek, Z. and G.L. Lövei. 2005. Ground beetle (Coleoptera, Carabidae) assemblages along an urbanization gradient near Sorø, Zealand, Denmark. Entomol. Med. 73:115-121.

Elek, Z., G.L. Lövei. 2007. Patterns in ground beetle (Coleoptera: Carabidae) assemblages along an urbanization gradient in Denmark. Acta Oecol. 32:104-111.

Farkas, S. 1998. Population dynamics, spatial distribution, and sex ratio of Trachelipus rathkei (Brandt, 1833) (Isopoda: Oniscidea) in a wetland forest by the Drava River. Isr. J. Zool. 44:323-332.

Fazekas, J., F. Kádár, M. Sárospataki and G.L. Lövei, 1997. Seasona activity, age structure and egg production of the ground beetle Anisodactylus signatus (Coleoptera: Carabidae) in Hungary. Eur J. Entomol. 94:473-484.

Fisher, R.A. 1930. The Genetical Theory of Natural Selection. Clarendon Press, Oxford, UK

Grimm, N.B., S.H. Faeth, N.E. Golubiewski, C.L. Redman, J. Wu, X. Bai and J.M. Briggs. 2008. Global change and the ecology of cities, Science 319:756-760.

Godfray, H.C.J. and J.H Werren. 1996. Recent developments in sex ratio studies. Trends. Ecol. Evol. 11:59-63.

Gonçalves, S.C., M.A. Pardal, P.G. Cardoso, S.M. Ferreira and J.C. Marques. 2005. Biology, population dynamics and secondary production of Tylos europaeus (Isopoda, Tylidae) on the western coast of Portugal. Marine Biol. 147:631-641.

Holway, D.A. and A.V. Suarez. 2006. Homogenization of ant communities in mediterranean California: the effects of urbanization and invasion. Biol. Conserv. 127:319-326.

Hornung, E. and M.R. Warburg. 1998. Plasticity of a Porcellio ficulneus population under extrem weather conditions (a case study). Isr. J. Zool. 44:395-398.

Hornung, E., B. Tóthmérész, T. Magura and F. Vilisics. 2007. Changes of isopod assemblages along an urban - suburban - rural gradient in Hungary. Eur. J. Soil Biol. 44:158-165.

Horváth, R., Z. Elek and G.L.Lövei. 2014. Compositional changes in spider (Araneae) assemblages along an urbanisation gradient near a Danish town. Bull. Insectology 67:255-264.

Magura,T., G.L. Lövei and B. Tóthmérész. 2010. Does urbanization decrease diversity in ground beetle (Carabidae) assemblages? Global Ecol. Biogeogr. 19:16-26.

Meinertz, T. 1964.The distribution of the terrestrial isopods in Denmark up to 1963. Vidensk. Medd. Dan. Naturhist. Foren. 126:465-496.
McIntyre, N.E., J. Rango, W.F. Fagan and S.H. Faeth. 2001. Ground arthropod community structure in a heterogeneous urban environment. Landscape Urb. Plan. 52:257-274.

Nair, G.A. 1998. Reproductive and population biology of Porcellio scaber (Isopoda, Oniscidea) in Benghazi, Libya. Isr. J. Zool. 44:399-412.

Niemelä, J., J. Kotze, A. Ashworth, P. Brandmayr, K. Desender, T. New, L. Penev, M. Samways and J. Spence. 2000. The search for common anthropogenic impacts on biodiversity: a global network. J. Ins.Conserv. 4:3-9.

Niemelä, J., J.H. Breuste, G. Guntenspergen, N.E. McIntyre, T. Elmqvist and P. James, 2011. Urban Ecology - Patterns, Processes, and Applications. Oxford University Press, Oxford, UK

O’Neill, S.L., A.A. Hoffmann and J.H. Werren, 1997. Influential Passengers: Inherited Microorganisms and Invertebrate Reproduction. Oxford University Press, Oxford, UK

Paoletti, M.G. and C.M. Cantarino. 2002. Sex ratio alterations in terrestrial woodlice populations (Isopoda: Oniscidea) from agroecosystems subjected to different agricultural practices in Italy. Appl. Soil. Ecol. 19:113-120.

Pavao-Zuckerman, M.A. and D.C. Coleman. 2007. Urbanization alters the functional composition, but not taxonomic diversity, of the soil nematode community. App. Soil Ecol. 35:329-339.

Rigaud, T., D. Antoine, I. Marcede and P. Juchault. 1997. The effect of temperature on sex ratio in the isopod Porcellionides pruinosus: Environmental sex determination or a by-product of cytoplasmic sex determination? Evol. Ecol. 11:205-215.

Roques, A., W. Rabitsch, J.Y. Rasplus, C. Lopez-Vaamonde, W. Nentwig and M. Kenis. 2009. Alien Terrestrial Invertebrates of Europe. Handbook of Alien Species in Europe. Invading Nature - Springer Series in Invasion Ecology 3, pp. 63-79.

Sapia, M., G.L. Lövei and Z. Elek. 2006. Effects of varying sampling effort on the observed diversity of carabids (Coleoptera: Carabidae). Ent. Fenn. 17:345-350.

Sattler, T., P. Duelli, M.K. Obrist, R. Arlettaz and M. Moretti. 2010. Response of arthropod species richness and functional groups to urban habitat structure and management. Landscape Ecol. 25:941-954

Scharff, N. and O. Gudik-Sørensen, 2006. Catalogue of the Spiders of Denmark (Araneae), Entomol. Medd. 74:3-71.

Schmalfuss, H. 2003. World catalog of terrestrial isopods (Isopoda: Oniscidea). Stuttg. Beitr. Naturk., Ser. A 654:1-341.

Schowalter, T.D. 2012. Insect responses to major landscape-level disturbance. Annu. Rev. Entomol. 57:1-20.

Sutton, S.L. 1980. Woodlice. Pergamon Press, Oxford, UK.

Sunderland, K.D., M. Hassall and S.L. Sutton. 1976. The population dynamics of Philoscia muscorum (Crustacea, Oniscoidea) in a dune grassland ecosystem. J. Anim. Ecol. 45:487-506.

Tian, G., L. Brussard and B.T. Tang. 1995., Breakdown of plant residues with contrasting chemical composition under humid tropical conditions: effects of earthworms and millipedes. Soil Biol. Biochem. 27:277-280.

Tuf, I.H. 2003. Development of the community structure of terrestrial isopods (Crustacea, Isopoda, Oniscidea) after a summer flood. In: A. Sfenthourakis, P.B. Araujo, E. Hornung, H. Schmalfuss, S. Taiti and K. Szlávecz (eds.), The Biology of Terrestrial Isopods $V$. (Crustaceana Monographs, 2), Brill Academic Publisher, Leiden, pp. 231-242.

Vilisics, F., Z. Elek., G.L. Lövei and E. Hornung. 2007. Composition of terrestrial isopod assemblages under different urbanization stages in Denmark. Pedobiologia 51:45-53. 
Vilisics, F. and E. Hornung. 2009. Urban areas as introduction hot-spots and shelters for native isopod species. Urban Ecosyst. 12:333-345.

Vilisics, F., D. Bogyó, T. Sattler and M. Moretti. 2012. Occurrence and assemblage composition of millipedes (Myriapoda, Diplopoda) and terrestrial isopods (Crustacea, Isopoda, Oniscidea) in urban areas of Switzerland. ZooKeys 176:199-214.

Wijnhoven, H. 2000. Landpissebedden van de Ooijpolder: deel 1. verspreiding (Crustacea: Isopoda: Oniscidea). Nederl. Faunist. Med. 11:55-131.
Zapparoli, M. 1997. Urban development and insect biodiversity of the Rome area, Italy. Landscape Urban Plan. 38:77-86.

Zimmer, M. and G. Kautz. 1997. Breeding phonological strategies of the common woodlouse, Porcellio scaber (Isopoda: Oniscidea). Eur. J. Soil Biol. 33:67-73.

Zimmer, M. and W. Topp. 1999. Relationships between woodlice (Isopoda: Oniscidea)and microbial density and activity in the field. Biol. Fert. Soils 30:117-123.

Received January 15, 2018 Revised May 20, 2018 Accepted June 4, 2018 